\title{
Dejar como verbo de causatividad positiva
} Dejar (let) as a Positive Causation Verb

\author{
Julieta Castellanos Armenta \\ Universidad Autónoma de Querétaro \\ yecasar@gmail.com
}

\author{
Ricardo Maldonado Soto \\ Universidad Nacional Autónoma de México/ \\ Universidad Autónoma de Querétaro \\ ricamaso@gmail.com
}

\section{Resumen}

Este trabajo describe las condiciones semánticas y sintácticas de las estructuras complejas de dejar + infinitvo y dejar + gerundio con lectura de causatividad positiva. Con datos obtenidos de corpora del español mexicano del siglo $\mathrm{xx}$, mostramos que el tipo de causatividad de estas estructuras se determina por la manera en que se impone la fuerza causante —en términos del modelo Dinámica de fuerzas (Talmy, 1988) —, la cual se relaciona con la naturaleza del verbo, los rasgos del estímulo que incita el evento y la reacción del causado (participación/resistencia) ante la provocación a la que es sometido.

Palabras Clave: causatividad positiva, dinámica de fuerzas, estructuras complejas, causativas en español

\section{Abstract}

This paper describes the semantic and syntactic conditions determining causative constructions with dejar (dejar + infinitive/gerund) inducing positive causation. Based on 20th century Mexican Spanish data, we will argue that the type of causation of these structures is determined by the way in which the causative force is imposed - according to Force Dynamics (Talmy, 1988). This is determined by the verb internal structure, the features of the stimulus inciting the event and the reaction of the causee to the main event impulse (resistance/participation).

KEYwORDS: positive causation, Force Dynamics, complex structures, Spanish causatives

FECHA DE RECEPCIÓN: 18/06/2019

FeCHA DE ACEPTACIÓN: 03/10/2019 


\section{Introducción}

Las construcciones causativas analíticas han sido analizadas tradicionalmente con énfasis en estructuras factitivas con el verbo hacer (Curnow, 1993; Davies, 1995; Paris, 1999; Enghels, 2012; García, 2013; Vivanco, 2016; López, 2017; Vera, 2018) con complemento infinitivo (1a) o con cláusula completiva (1b). Esta clase de oraciones bipredicativas ha sido utilizada como prototipo de situaciones en las que un sujeto causante (SCte) provoca que un sujeto causado (SCdo) realice un evento.

(1) a. Grijalva hizo redactar al notario Diego de Godoy una escritura SCte SCdo (CREA)

b. El líder separatista hizo que sus fieles cambiaran la porra que SCte SCdo gritaban (CREA)

La estructura semántica del evento complejo responde a la siguiente representación esquemática:

\section{(2) [SCte CAUSAR [SCdo HACER]}

Más interesante es el reconocimiento de la existencia de eventos en los que el SCte no induce el acto impuesto sobre el SCdo. En el marco de su teoría de Dinámica de fuerzas Talmy (1988) opone estos eventos a los de causatividad positiva y los considera como procesos de causatividad negativa. En ellos, el SCte no es impositivo y el SCdo se presenta como una entidad con menos control y responsabilidad en la ejecución del evento. Lo aquí entendido como causatividad negativa comprende situaciones con verbos causativos permisivos tales como consentir, permitir y dejar que expresan eventos no implicativos y según los cuales la presencia de un SCte tiene poco control sobre la ejecución de un segundo evento a manos de SCdo, como se ejemplifica en (3a-b).

(3) a. Tal vez por ello los padres (...) le permitieron trabajar en la escuela SCte SCdo (CREA) 
b. Se iba a morir por eso [él] dejó que su hermano comprara el terreno SCte SCdo2 (CREA)

En vez de definirse bajo CAUSAR, su configuración básica responde a PERMITIR, como en (4):

(4) [SCte PERMITIR [SCdo HACER]]

Si bien dejar y permitir se asocian prototípicamente con la causación negativa, es pertinente analizar los contextos sintácticos bajo los cuales los verbos permisivos pueden imponer causación positiva. El movimiento de causación negativa a positiva con dejar se puede observar en los siguientes casos. Dejar se une al complemento representativo de las construcciones causativas factitivas: esto es, una cláusula completiva (5a) o de infinitivo (5b), y opera como un verbo de causatividad negativa al contener un SCte que no se impone sobre la actuación de SCdo. Sin embargo, esa no es la única interpretación para este verbo en contexto causativo, como lo ejemplifican (6a) y (6b):

(5) a. Agustín, tácitamente, dejó que Primitiva tomara el papel femenino SCte SCdo (CREA)

[SCte PERMITIR [SCdo HACER]]

b. [Estuvo] esperando que él se diera cuenta de que ella lo dejó ir SCteSCdo (CREA) [SCte PERMITIR [SCdo HACER]]

(6) a. De pronto escuché un balazo que me dejó congelado (CREA) SCte SCdo

b. Recibió en los riñones una puñalada que lo dejó agonizando, durante horas SCte SCdo (MD)

Para (6a-b), la representación esquemática coincide con CAUSAR pero el predicado causado se define como CAMBIAR A NUEVO ESTADO o SITUACIÓN, como se representa en (7): 
Si en la construcción causativa con dejar se reemplaza la cláusula completiva o el infinitivo por cualquiera de los otros dos verboides, la estructura ya no corresponde a una causatividad negativa, ni a la interpretación permisiva del verbo. Se cuenta ahora con construcciones formadas por dos subeventos: una causa y un resultado correspondiente a un cambio de estado, que, de hecho, conforman construcciones de causatividad positiva. Nótese que el sujeto causante de los ejemplos (6a-b; un balazo / una puñalada) es inanimado y no volitivo; en otras palabras, no coincide con las características de los sujetos causantes prototípicos (Grijalva / El líder separatista) de las estructuras factitivas con causatividad positiva (1a-b). El hecho de que (6a) y (7) contrasten tanto con (1a) y (1b) como con (5a) y (5b) exige decidir si estos casos representan situaciones causativas reales y, de ser así, qué tipo de causación reflejan. Estas cláusulas específicas con dejar no coinciden con la interpretación causativa negativa prototípica, ni tampoco satisfacen las peculiaridades de la causatividad positiva de las construcciones factitivas.

El objetivo del presente análisis es determinar las condiciones tanto sintácticas como semánticas que favorecen una interpretación de causatividad positiva en las cláusulas complejas dejar + participio/gerundio. Este trabajo parte de la hipótesis de que en las construcciones de causatividad positiva con dejar, mientras más alto sea el nivel de actividad de los participantes, mayor independencia habrá entre los subeventos de la construcción y ello hará que la lectura causativa disminuya.

El análisis se hace con base en una muestra de 250 casos de los patrones dejar + participio y dejar + gerundio, obtenidos de corpora del español de México del siglo xx.

Nuestra discusión inicia con la caracterización del fenómeno de la causatividad, entendido como un evento complejo, así como con la consideración de las características de sus participantes y su modo de interactuar $(\$ 1)$; seguimos con un recuento de análisis previos de verbos del tipo dejar en situación causativa (\$2); describimos las restricciones semánticas y sintácticas 
que determinan que las cláusulas complejas dejar + participio/ gerundio puedan ser consideradas como construcciones de causatividad positiva $(\$ 3)$ y, finalmente, ponemos a consideración los resultados y las conclusiones del estudio.

\section{Causatividad}

\section{Construcciones causativas analíticas}

Las construcciones sintácticas representan la forma en que los hablantes conciben la realización de los eventos a su alrededor. Hay eventos que suceden por sí mismos; hay otros que ocurren por la inducción o la responsabilidad de algo o alguien, como también hay otros que sólo muestran el resultado de un evento. Cada tipo de evento se refleja en la lengua por medio de mecanismos formales distintos.

Las lenguas del mundo registran tres codificaciones como las más comunes para manifestar situaciones causativas: la morfológica, la léxica y la analítica o perifrástica (Comrie, 1989). Este trabajo se centra en las construcciones causativas analíticas.

En la causatividad analítica, la causa y el resultado se expresan mediante dos predicados morfológicamente independientes, como se ilustra en el siguiente ejemplo:
John made Paul eat the apples
John hacer-PST-3Sg Paul comer-SBJV-3Sg ART.PL manzana.PL 'John hizo que Paul comiera las manzanas'
SCte
SCdo
(Comrie, 1989, p. 179)

Cuya estructura corresponde a [SCte CAUSAR [SCdo HACER]]. El caso expuesto en (8) corresponde a una construcción causativa analítica en la que la causa es expresada por la cláusula [SCte CAUSAR: John made] y el resultado se manifiesta con [SCdo HACER: Paul eat the apples], lo que nos muestra la existencia de dos predicados asociados en forma causal. 


\subsection{Factores para la integración de un evento complejo}

Las dimensiones semánticas y sintácticas necesarias para la integración de un evento complejo se asocian con el principio de iconicidad (Givon, 2001), según el cual, entre más fuerte sea el vínculo semántico entre los dos subeventos, mayor será la integración sintáctica entre las dos cláusulas para fusionarse en una sola cláusula compleja. La dimensión semántica de la integración de un evento es gradual; dicha organización está determinada por el verbo principal. Givon (2001) distingue la integración de subeventos en cláusulas complejas con verbos modales, verbos de manipulación y los verbos de percepción y cognición. Los verbos modales y los de manipulación se encuentran en una situación paralela en la escala de la integración de un evento y van desde el punto más alto a los grados medios de integración. Más abajo en la escala, están los verbos de percepción que descienden hasta los grados más bajos de integración.

Los verbos de manipulación (hacer, ordenar, obligar), a su vez, se dividen en dos grupos: los que logran una manipulación exitosa (implicativos) (9a) y los que sólo denotan la intención de manipular (no implicativos) (9b).

(9) a. She made him shave

PRON.3SG.F hacer-PST-3SG ACC.3sG.M afeitar-SBJV-3sG

'Ella hizo que se afeitara'

(Givon, 2001, p. 43)

b. She told him to leave

PRON.3SG.F decir-PST-3SG DAT.3SG.M irse-INF

'Ella le dijo que se fuera'

(Givon, 2001, p. 48)

En este estudio nos enfocaremos en la descripción de los rasgos que determinan la integración de eventos con verbos causativos implicativos.

En lo que respecta a las condiciones semánticas y sintácticas prototípicas de una cláusula compleja con verbos implicativos de manipulación exitosa, Givon (2001, p. 41) sugiere aten- 
der al CONTROL, ELECCión e INDEPENDENCIA. De acuerdo con estos tres aspectos, se observa que:

- El sujeto causante se impone al sujeto causado, presentado como un agente potencial pero con menos control, menos capacidad de elección o menos independencia para actuar.

- El sujeto causado es más pacientivo.

- El evento causado codifica lo desempeñado por el sujeto causado.

- En la cláusula principal, el agente del evento causante funge como sujeto y el sujeto del evento causado puede además aparecer como objeto directo (9a) u objeto indirecto (9b) de la cláusula principal.

- El verbo de manipulación corresponde al verbo pleno de la cláusula principal.

Acerca de la correlación entre agentividad y logro manipulativo, se dice que entre más exitosa sea una manipulación, menos control tiene el causado y es, consecuentemente, menos agentivo (Givón, 2001, p. 45). En (9a), un ejemplo de verbo implicativo causativo, el sujeto causado es menos agentivo; cuenta con menor libertad y control para realizar lo que le han mandado hacer que cuando opera en forma independiente. Por el contrario, en (9b) el sujeto causado tiene mayor control, independencia y capacidad de elección para realizar el evento inducido. El verbo que lo controla no es implicativo.

Entre más directa sea la manipulación del causante sobre el causado, más probable es que se logre el evento causado (Givon, 2001, p. 48). Por tal razón, verbos como hacer y forzar codifican una manipulación exitosa directa e intencionada, aunque a nivel léxico, entre ambos verbos hay una diferencia gradual importante en la escala de manipulación. Ahora bien, el éxito de una manipulación no está determinado únicamente por cuán directo sea el contacto entre los participantes. Intervienen también otras dimensiones como la resistencia y la fuerza coercitiva. Es decir, interviene no sólo la fuerza del causante, sino también la capacidad de resistencia del causado.

Las dimensiones semánticas de la causatividad pueden ser agrupadas en tres grandes grupos: a) el tipo de verbo, b) las pro- 
piedades del causado y c) las propiedades del causante (Dixon y Aikenvhald, 2000, p. 61):

a) En relación con el verbo. Al hablar de la semántica verbal debe tomarse en cuenta si el verbo del evento causado se refiere sólo a estados o también a acciones; si el significado causativo implica verbos causados intransitivos, transitivos o ditransitivos.

b) En relación con el causado. Hay que verificar si el sujeto causado es el sujeto de un verbo transitivo (A) o de uno intransitivo (S). Los parámetros semánticos que lo atañen tienen que ver con el control y la volición del sujeto causado, así como con su grado de afectación (completa o parcial), al realizar la actividad.

c) En relación con el causante. A pesar de que el sujeto causante siempre tiene carácter de sujeto transitivo (A), habrá que considerar cuán directa es la interacción entre el causante y el causado; si el causante logra el resultado por accidente o intencionalmente; si el causante provoca el evento como un proceso natural, o si implica un esfuerzo que pueda presuponer desgaste, violencia, etc.; si el causante se involucra en la actividad.

Esta lista de parámetros es sólo tentativa y no es discreta. Además de que es altamente probable que varios de estos factores sean interdependientes.

\subsection{Tipos de causatividad y sus participantes}

- $\quad$ Positiva vs. negativa

En términos de la presencia o ausencia de la fuerza del sujeto causante sobre el sujeto causado, Talmy (1988, p. 57) hace la distinción entre la causación positiva y causación negativa. En la primera, el causante impone su fuerza sobre el causado para que éste actúe. Por su parte, en la causación negativa, no hay intervención del causante para que el causado continúe con su tendencia a actuar. 
Quizá la distinción semántica más común que se ha hecho para la causatividad sea la diferencia entre lo físico y lo mental. Aunque no se cuenta con definiciones rigurosas, las situaciones causativas que habremos de tomar en cuenta son:

- $\quad$ Física (no verbal): el causante impone un cambio de estado a un causado a través de contacto físico. Sus participantes son: un causante agente, volitivo e instigador con alto control y un causado no volitivo, afectado, sin control. Se manifiesta generalmente con eventos implicativos y los subeventos son inmediatos, casi simultáneos.

- Verbal (mental): el causante provoca que el causado lleve a cabo una acción o se vea afectado por un proceso de cambio, generalmente por predicados de actos de habla. La naturaleza característica de sus participantes está determinada por la volición del causado, por lo común, animado, que puede poner resistencia al control del causante. En la verbal, se expresan eventos no implicativos y secuenciales.

Estudios de corte tipológico coinciden en que el causante aparece como humano y frecuentemente es activo; su intervención puede ser física o mental, esto depende de la naturaleza de la situación y del tipo de sujeto causado con el que se interactúa. Es esperable que entre más activo o agentivo sea el causado, más factible es que se trate de una causatividad no física (VelázquezCastillo, 2002, p. 517).

El causado, con frecuencia, es humano, pero también puede presentarse como una entidad inanimada. La naturaleza del causado depende de la naturaleza del predicado; la actividad del causado juega un rol importante en el grado de la fuerza de la causatividad expresada. Entre más activamente se involucre el causado, más alto es el nivel de resistencia y más fuerte será la necesidad de incrementar la fuerza en la intervención del causante (Velázquez-Castillo, 2002, p. 518).

Sin embargo, hay que reconocer que estos roles y su naturaleza pueden manifestarse de forma distinta en lenguas con 
construcciones causativas particulares donde el grado de causatividad puede variar.

\subsection{Interacción de participantes}

La interacción de las entidades participantes en una situación causativa puede ser analizada en términos de Dinámica de fuerzas (Talmy, 1988). Ésta es una propuesta que va más allá de la noción tradicional de causatividad lingüística para exponer la interacción de las entidades con respecto a su fuerza; desde esta perspectiva, causar incluye los conceptos 'permitir', 'impedir', 'ayudar', y algunas otras nociones del mismo contexto que generalmente no son consideradas como causativas.

Los patrones básicos de la Dinámica de fuerzas corresponden a la oposición de dos fuerzas en estado estable. La distinción elemental que marca una lengua con referencia a la interacción de dos entidades es una diferencia de rol entre estos participantes. Una entidad que ejerce su fuerza se elige por atención focal - el resultado de la interacción es si esta entidad es capaz de mantener su tendencia de fuerza o, por el contrario, es supera$\mathrm{da}-$. La segunda entidad es considerada por el efecto que tiene en la primera, si la contrarresta o no. La entidad de fuerza focal es el agonista (lo que hasta ahora hemos llamado causante) y la entidad de la fuerza que se opone es el antagonista (a la que nos hemos referido como causado).

La fuerza de cada entidad es relativa: la entidad capaz de manifestar su tendencia, a pesar de su oponente, es la de mayor fuerza; siendo, en este caso, el oponente, el de menor fuerza. La interacción produce como resultado ya sea el movimiento o el reposo del agonista, cuya circunstancia es la que está en juego.

\section{Verbos del tipo dejar en situación causativa}

A pesar de que existen algunas referencias sobre let (dejar) en situación causativa (Givon, 2001 y en los trabajos incluidos en Shibatani, 2002), son escasos los análisis lingüísticos específicos sobre verbos del tipo dejar como verbo causativo en otras lenguas. Entre estos destacan el estudio de Verhagen y Kemmer (1997) 
sobre doen (hacer) y laten (dejar) en neerlandés, los estudios de Rodríguez-Espiñeira (1999) para el español, las aportaciones de Soares da Silva para deixar en portugués (2003, 2004a, 2004b, 2007 y otros), el de Maldonado y Nava sobre el tarasco (2001) y los análisis de Enghels y Roegiest de laisser en francés y sus comparaciones con el español (2012) y, finalmente, el de Enghels (2013).

Los estudios previos coinciden en la importancia de reconocer la necesidad de contar con una categorización adecuada para la situación causativa que implica dejar, ajena a los prototipos de causatividad factitiva-implicativa. En menor o mayor grado, los estudios mencionados coinciden en que los parámetros semánticos de los argumentos estructurales están en correlación con las condiciones sintácticas para establecer el tipo de causatividad de una construcción. También concuerdan en que la interacción de los participantes es determinante para el significado causativo por lo que consideran que una opción viable para analizarla es el modelo de Dinámica de fuerzas (Talmy, 1988).

No obstante, es necesario refinar el análisis para reconocer que dejar no sólo implica una causatividad negativa, sino que, en determinados contextos con características específicas, puede designar causatividad positiva.

\subsection{Estructuras complejas con dejar en español mexicano}

Son cinco las cualidades sintácticas de las estructuras complejas en las que aparece el verbo dejar, en español mexicano: dejar + cláusula completiva (10a), dejar + infinitivo (10b), dejar + participio(10c), dejar+gerundio(10d)ydejar+verboenindicativo(10e).

(10)a. (...) pero dejó que al indio casi lo mataran

b. Yordan no la dejó acabar porque prendió la luz

c. El peso de esta revelación me dejó anonadado...

d. Los dejé hablando y me vine porque era hora de clase

e. Déjame veo si lo tengo

(Maldonado, 2000, p. 281)

Los ejemplos anteriores (10a-e) pueden ser divididos en tres grandes grupos, atendiendo a su sintaxis: el primero correspon- 
de a la construcción mostrada en (10a), reconocida por la gramática tradicional del español como estructura completiva; en este ejemplo, dos cláusulas son unidas por el complementizador que, el cual introduce la segunda cláusula cuya forma verbal es finita. $\mathrm{Al}$ segundo grupo corresponden los ejemplos (10b-d), en los que el verbo dejar tiene complementos no finitos (infinitivo, participio y gerundio), sin ningún tipo de conector o subordinador, por lo que su estatus dentro de la sintaxis es un tanto controversial. Podría decirse que por tratarse de estructuras con complementos cuya forma verbal no está flexionada, estos ejemplos tenderían a ajustarse a las características de los predicados complejos o de las perífrasis verbales; sin embargo, también puede ser considerado como un fenómeno de unión de cláusulas (Gibson y Raposo, 1986). El tercer grupo corresponde al ejemplo (10e), en el que se observa la unión de dejar con un verbo en indicativo (veo), descrita como una construcción sometida a un proceso de desemantización en la que el sentido de causatividad se ve reducida a su mínima expresión, subrayando la independencia de acción del sujeto causado, por lo que "se sitúa en el punto limítrofe entre la causatividad y la concatenación coordinada de cláusulas" (Maldonado, 2000, p. 297).

Para llevar a cabo este análisis se ha conformado una muestra de 250 casos solamente de los patrones dejar + participio y dejar + gerundio, por ser las construcciones en las que se puede presentar una causatividad positiva. 115 ejemplos pertenecen al Corpus de Referencia del Español Actual (CREA) de la Real Academia Española; 25 cláusulas se obtuvieron del Corpus Sociolingüístico de la Ciudad de México (cscm) (Butragueño y Lastra, 2011) y 110 casos fueron extraídos del Corpus del Español de Mark Davies (MD) (Davies, 2002).

Del total de cláusulas analizadas (250), se hizo una separación de las estructuras con base en tres interpretaciones: a) no causativa (11a-b), con una secuencia de eventos sin relación de causa y resultado, en los que hay dos entidades que actúan de manera independiente; b) causativa positiva (12a-b), con dos eventos como una causa y un resultado; y c) una interpretación ambigua (13a-b), en la que se puede percibir tanto una interpretación causativa como otra no causativa. 
(11) No causativa: se distinguen dos eventos independientes simultáneos, sin relación de causa y efecto

a. Al ver al niño en su cama, no quiso despertarlo y (ella) lo lo dejó dormido $(\mathrm{MD})$

S1 S2

[S1 HACER] // [S2 HACER]

b. Poco faltó para que les dijera, sin embozo, que les (él) dejaba deteS2 S1

niendo las peñas, mientras él corría a dar la buena nueva

(MD) [S1 HACER] // [S2 HACER]

(12) Causativa positiva: Es la secuencia de dos eventos en una relación de causa y resultado.

a. La influencia que mi tío tenía en Cuévano me dejó asombrado

SCte

SCdo

(CREA)

[SCte CAUSAR [SCdo CAMBIAR A NUEVO ESTADO]]

b. Recibió en los riñones una puñalada que lo dejó agonizando, durante horas SCte SCdo (MD) [SCte CAUSAR [SCdo CAMBIAR A NUEVA SITUACIÓN]]

(13) Ambigua: Se perciben dos interpretaciones: una causativa y otra, no causativa.

a. Hizo un esfuerzo supremo y (él) le levantó y le dejó desmayado sobre la cornisa

Opción 1:S1

Opción 2:SCte
S2

SCdo (CREA)

Opción 1: dos eventos independientes simultáneos.

[S1 HACER] // [S2 CAMBIAR]

Opción 2: dos eventos en relación de causa y resultado.

[SCte CAUSA [SCdo CAMBIAR A NUEVo ESTADo]]

b. (Yo) Los dejé hablando y me vine, porque era hora de clase (MD)

Opción 1:S1 S2

Opción 2:SCte SCdo 
Opción 1: dos eventos independientes simultáneos.

[S1 HACER] // [S2 CAMBIAR]

Opción 2: dos eventos en relación de causa y resultado.

[SCte CAUSA [SCdo CAMBIAR A NUEVA SITUACIÓN]]

La construcción causativa positiva merece un análisis detallado.

\section{Causatividad positiva resultativa en dejar + participio y dejar + gerundio}

Las razones por las que las construcciones dejar + participio y dejar + gerundio pueden exponer una situación causativa son la presencia de una causa y un resultado, como parámetro sintáctico básico (Comrie, 1989); la conformación de un núcleo predicativo a partir de dos verbos en fusión (Comrie, 1976) y la morfología del verbo de las dos predicaciones; además, la imposición de una fuerza causante sobre un causado (Talmy, 1988) (cfr. $\$ 1$ de este documento).

Para ser causativas, las construcciones deben contar con un predicado que expresa causa y otro que expresa efecto, que es causalmente dependiente del primero (Shibatani, 1976; Comrie, 1985; Verhagen y Kemmer, 1994), como en los ejemplos (14a-b):

(14) a. Recibió en el punto más sensible de todo su ser, una herida que lo había dejado vacilando sobre sus débiles pies, tambaleándose (CREA)

b. En sólo 9 días, Alexis vivió una tragedia que lo ha dejado marcado para siempre

En (14a), la causa y el resultado se manifiestan [Una herida CAUSAR [Él CAMBIAR DE SITUACIÓN (vacila sobre sus débiles pies)]]. En (14b), los subeventos se vinculan [Una tragedia CAUSAR [Él CAMBIAR DE ESTADO (se marca para siempre)]]. Así, los dos ejemplos anteriores son estructuras complejas bipredicativas que expresan que un primer evento causa la realización de otro. En ambos casos, sólo el verbo de la cláusula principal dejar aparece como verbo pleno conjugado, mientras que en la 
segunda cláusula hay un verboide. Al unirse ambas formas, dejar se desemantiza $\mathrm{y}$, junto con el participio/gerundio forman el núcleo de la estructura compleja, en la que el verboide funge como complemento predicativo.

En (14a) dejar y vacilando constituyen una construcción con dos predicados, tal como sucede con los verbos causativos analíticos (Comrie, 1976) y lo mismo pasa en (14b) con ha dejado y marcado. En ninguno de los dos ejemplos expuestos dejar se refiere a su significado léxico 'soltar'. Sin embargo, no se trata de una unión verbal sintáctica de fusión inalterable ya que podría interponerse entre ellos una frase nominal, sin modificar el sentido de causatividad. Podríamos encontrar casos como había dejado al hombre vacilando y ha dejado a Alexis marcado.

En lo que respecta a los participantes: una herida en (14a) y la tragedia en (14b), con función de sujetos en la cláusula principal, les corresponde el rol de causante y los que aparecen como sujetos causados aparecen como acusativos pronominales de tercera persona en singular masculino (lo). En estos casos, los causantes se expresan en forma léxica y los causados son pronominales; sin embargo, ésta no es una restricción sintáctica. Es aceptable que ambos aparezcan en cualquiera de las dos formas sin provocar alteraciones (Una tragedia que lo ha dejado marcado; Una tragedia que ha dejado marcado a Alexis).

En resumen, las construcciones dejar + participio/gerundio coinciden con las condiciones sintácticas de las estructuras complejas causativas porque están conformadas por dos predicados que presentan una causa y un efecto; su núcleo predicativo está conformado por dos elementos verbales con distinta morfología que se fusionan para referir un solo significado causativo, aunque con cierta flexibilidad en su integración sintáctica y sus participantes corresponden a los roles de un causante y un causado, ya sea en forma léxica o pronominal.

\subsection{Interpretación causativa positiva resultativa}

En los ejemplos de lectura causativa positiva (12a-b) la atención debe dirigirse al efecto de dejar que, a pesar de no ser considerado como verbo causativo prototípico, conforma una estructu- 
ra biclausal en la que se distingue la presencia de un subevento (causa) que propicia la generación de un segundo subevento (resultado). Es decir, en (12a), La influencia que tenía mi tío en Cuévano provoca el asombro del participante que aparece en primera persona de singular (me); así también en (12b), una puñalada causa que agonice un segundo participante.

Nótese además que La influencia... (12a) y una puñalada (12b), por tratarse de las entidades de fuerza focal, son entendidas como agonistas (Talmy, 1988); por otro lado, las fuerzas opositoras o antagonistas están expresadas por una primera persona de singular, codificada por el pronombre me y una tercera persona de singular, el pronombre lo. El significado causativo de los ejemplos anteriores se determina por la generación de un cambio inducido: asombrado y agonizando, referidos como estados finales de un proceso. En consecuencia, la causatividad positiva de estos ejemplos es resultativa; es decir, se trata de eventos de manipulación efectuada puesto que la interacción de las entidades se refleja por el hecho de que el causante impone su fuerza sobre el causado en quien provoca un cambio de estado. Este modo de construcción se opone radicalmente a la interacción entre los participantes de situaciones de causatividad negativa, tradicionalmente reconocida en las construcciones con verbos del tipo dejar, que implica la no interferencia o no intervención del causante (Verhagen y Kemmer, 1994; Soares, 2004b). En contraste, dejar + participio y dejar + gerundio son patrones sintácticos con la posibilidad de una interpretación de causatividad positiva resultativa.

\subsubsection{Tipos de causatividad positiva resultativa}

A partir de la revisión de los ejemplos reunidos, encontramos que la causatividad positiva resultativa de dejar + participio/ gerundio puede ser generada: a) por un estímulo explícito y b) por un estímulo asociado, según la manera en que se efectúa la imposición de fuerza del causante sobre el causado, provocando un cambio de estado, ya sea físico o mental.

\section{A. Imposición de fuerza por un estímulo explícito}

En la imposición de fuerza por un estímulo explícito, el sujeto causante es un estímulo evidente que impone su fuerza en el 
causado, mediante un contacto real y sin intermediarios, provocando en éste un cambio de estado o de situación. A su vez, esta imposición de fuerza puede dividirse en dos subtipos, de acuerdo con el tipo de afectación que se provoca en el causado: con afectación física (15a-b) y con afectación mental, expuestas más adelante en (16a-b):

(15)a. Un garrotazo en la columna, a la altura del coxis, que lo dejó desmayado y con herida sangrante

(CREA)

b. Le clavó tan hondo un cuchillazo al monstruo que lo dejó sangrando morado

La interpretación causativa de los ejemplos anteriores está determinada por la imposición de la fuerza de los causantes (un garrotazo / un cuchillazo) que, mediante un contacto real y sin intermediarios, ha provocado en los causados (tercera persona de singular, referido por lo) un cambio de situación como estado final: de estar consciente a desmayado en (15a) y de no sangrar a estar sangrando (15b), lo cual se interpreta como una causatividad resultativa. A partir de la interacción de las entidades de (15a-b), proponemos el siguiente esquema para representar el tipo de imposición de fuerza por un estímulo explícito con afectación física en los patrones sintácticos dejar + participio y dejar + gerundio en la construcción causativa positiva de orden resultativo.

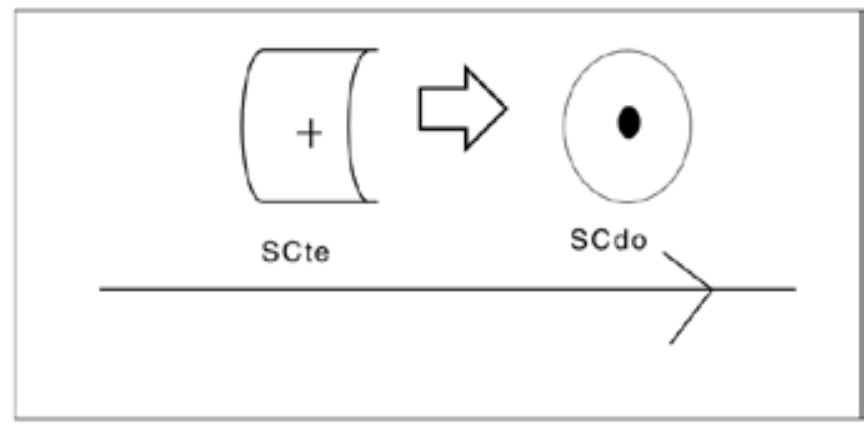

Esquema 1. Interacción de participantes en la imposición de fuerza directa con afectación física 
En el esquema 1, observamos la interacción del causante, simbolizado por una figura cóncava que posee una fuerza mayor (+) que el causado (- activo), representado por un círculo, en estado estable o reposo (el punto negro). La flecha de línea continua que va del causante al causado significa la dirección en la que se orienta la fuerza de manera directa y concreta. Por último, la línea horizontal inferior simula la trayectoria, que en estos casos representa metafóricamente el proceso de cambio de estado, simbolizado por un ángulo de izquierda a derecha.

Al aplicarlo a los ejemplos (15a-b), tenemos que los causantes, entidades más fuertes, están codificados en ambos casos por sustantivos eventivos (un garrotazo / un cuchillazo), los cuales imponen su fuerza, directa y concretamente sobre los causados (él / un monstruo) provocando afectaciones físicas, representadas por el participio desmayado y el gerundio sangrando, ambas formas verbales no finitas de acciones en las que el sujeto causado es un participante sin volición. Es válido, por tanto, decir que la lectura causativa de dejar + participio y dejar + gerundio se determina a partir de la imposición de la fuerza de un estímulo explícito, de manera directa y con afectación física, sobre una entidad causada, con rol de experimentante, que sufre un cambio de estado o de situación.

La imposición de fuerza por un estímulo explícito con afectación mental se diferencia de la afectación física en que aquella no es tangible; es decir, es transmitida directamente del causante al causado, pero es inmaterial, como se aprecia en (16a-b):

(16)a. Llegamos a aquella Cholula de los templos, que dejó asombrado a Cortés

(CREA)

b. El enclaustramiento empezó a perturbar mi concentración y el abandono de la inspiración me dejó pensando en la soledad y en la frustración que padecía

En (16a), el causante es aquella Cholula de los templos y el causado es Cortés; la primera impone su fuerza sobre el segundo de manera directa, pero mediante una metonimia, peculiaridad 
que la convierte en una abstracción. Esta estructura tiene interpretación causativa positiva-resultativa que se determina por la imposición ahora abstracta de la fuerza del causante directamente en el causado, provocando en éste un cambio de estado mental: un asombro. Así mismo, en (16b) se distinguen como participantes de la situación causativa el abandono de la inspiración, como fuerza causante, y una primera persona de singular (yo) - correferida por el pronombre me-como causado. Es el abandono de la inspiración lo que provoca de manera directa que yo piense; por tanto, en esta construcción el causante, de fuerza mayor, se impone sobre el causado (- dinámico) provocando una respuesta de afectación mental, que es generar un pensamiento.

Una de las funciones tanto del participio como del gerundio predicativo es describir el estado en el que se encuentran las entidades a las que afecta. Éste es precisamente el oficio de asombrado y pensando en los ejemplos anteriores: el participio y el gerundio especifican la nueva situación de los causados (Cortés / yo) como el resultado del cambio mental que padecen a causa de aquella Cholula de los templos / el abandono de la inspiración, respectivamente. Su esquematización es la siguiente:

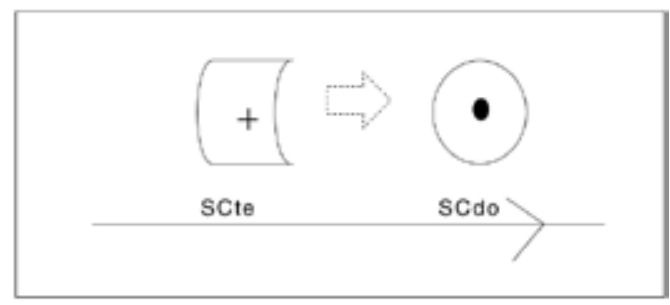

Esquema 2. Interacción de participantes en la imposición de fuerza directa con afectación mental

El esquema 2 sólo difiere del esquema 1 en que la flecha punteada simboliza el carácter abstracto de la fuerza, impuesta directamente sobre la entidad que opone resistencia. La línea horizontal inferior simula la trayectoria, que en estos casos corresponde a una metaforización del proceso de cambio de estado experimentado.

Tanto (16a) como (16b) constituyen ejemplos de dejar + participio y dejar + gerundio con lectura causativa positiva de 
índole resultativa, determinada a partir de la imposición de la fuerza abstracta por un estímulo explícito, de manera directa, sobre un causado con rol de experimentante, que padece un cambio de estado mental.

\section{B. Imposición de fuerza por un estímulo asociado}

Esta es una opción más en la que un causante impone su fuerza sobre el causado. Le hemos denominado imposición de fuerza por un estímulo asociado ya que no existe contacto real y palpable entre el antagonista y el agonista; una acción previa detona el cambio de estado del causado (17a-b):

(17)a. Y torció la llave de la araña, dejando alumbrado el gabinete, y la invitaba a sentarse

(CREA)

b. Que me digan de golpe y porrazo que escriba una historia, me deja vacilando

Tenemos en (17a) un causante humano en tercera persona de singular (torció) que volitivamente realiza una acción; el causado es un paciente (gabinete) que padece un cambio de estado situacional, denotado por un participio en función de complemento predicativo (alumbrado). Lo interesante es que el causante no impone directamente su fuerza sobre el causado para que su cambio de situación se lleve a cabo. Aunque existe una acción previa realizada en forma volitiva, la intención de esa acción (torcer la llave) no responde al deseo de causar que el gabinete quede alumbrado.

De la misma manera, en (17b) no hay un contacto directo entre las entidades participantes. Una acción previa (quienes dicen que escriba una historia) causa una nueva situación en el causado (dejar vacilando), sin que dicha acción conlleve la intención explícita de producir ese cambio de situación en el afectado. Remarquemos que los rasgos tanto del agente que realiza la acción para suscitar el cambio de estado, como del causado, son: [+ humano] [+ activo] [+ volitivo]. Sin embargo, el significado causativo de esta construcción se determina por una ac- 
ción anterior que no está orientada volitivamente a modificar al participante afectado.

En la imposición de fuerza por estímulo asociado, la fuerza opositora tampoco cumple con las condiciones agentivas, volitivas e intencionales que corresponden a los causantes prototípicos de las estructuras causativas. La fuerza impuesta es una acción previa volitiva que es interpretada como estímulo capaz de inducir un cambio de estado o de situación.

La representación esquemática que sugerimos para estructuras dejar + participio y dejar + gerundio con lectura causativa resultativa cuya imposición de fuerza proviene de estímulo asociado a una actividad previa es la siguiente:

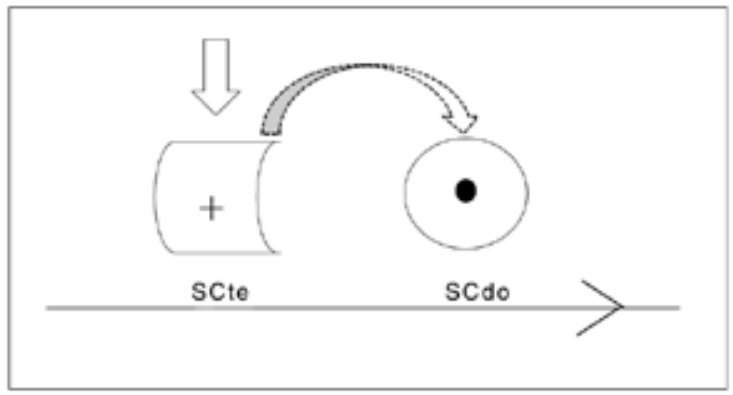

Esquema 3. Interacción de participantes en la imposición de fuerza indirecta

El esquema 3 representa un causante mediante una figura cóncava, de mayor fuerza $(+)$, que provoca de manera indirecta un cambio en el causado (- activo), simbolizado por un círculo en estado estable o de reposo. La flecha curva superior que va del causante al causado representa la dirección en la que se impone la fuerza de manera indirecta, mediante una acción previa, por lo que su contorno es punteado. La línea horizontal inferior representa metafóricamente el proceso de cambio de estado situacional. Es importante resaltar que, como se indicó antes, la acción previa del causante opera como estímulo para provocar el cambio de estado situacional del causado. Ésta es simbolizada por una flecha continua con dirección hacia abajo que afecta directamente al causado. 
Podemos concluir que las peculiaridades de una interpretación evidentemente causativa positiva de tipo resultativo en los patrones dejar + participio y dejar + gerundio son las siguientes:

a) El causante es representado como estímulo energético - codificado por un sustantivo eventivo como garrotazo, puñalada, balonazo - o por un sustantivo abstracto (acusación, enclaustramiento, frialdad) o por una metonimia (la belleza de Cholula, juventud, el efecto de una botella de cognac) o por una acción previa (y torció la llave de la araña, que me digan que escriba una historia). Estos impulsos ejercen una fuerza, de manera directa o indirecta sobre el causado provocando en éste un cambio de estado, ya sea físico, emocional o situacional.

b) El causado (- dinámico) debe ser un participante que experimenta una reacción involuntaria ante un impulso y que sufre un cambio de estado en una situación nueva.

c) En cuanto a los verbos de los que provienen el participio y el gerundio, existe una ligera diferencia. Como es de esperar, el participio sólo designa el resultado final de un cambio de estado provocado en un causado no activo; por tanto, la raíz de los participios en situación causativa resultativa responde a verbos de cambio de estado involuntario como admirar, asombrar, aterrar, desconcertar, pasmar. En lo que respecta al gerundio, son favorecidas las raíces de verbos inergativos involuntarios, como tambalear, titiritar, cojear y versiones inergativas de algunos verbos como llorar, hablar y charlar.

\subsection{Interpretación no causativa}

Dado el significado léxico del verbo dejar, existe la posibilidad de que dejar + participio y dejar + gerundio tengan una lectura no causal, como en (18a-b):

(18)a. Por fin había concluido una novela que por largo tiempo dejé abandonada

(CREA) 
b. Pablo, deseo volver al mar - decía el caracol; extraño el ruido de las olas. Llévame por favor al lugar de donde me sacaste. Pablo lo dejaba llorando (por sus añoranzas) en su agujero

Los ejemplos (18a-b) involucran una serie de eventos separados sin relación causal entre sí, con participantes que actúan en forma independiente. Por un lado, en (18a) está el evento principal, la culminación de la lectura o la escritura de una novela, unido a una oración subordinada con la función de complemento nominal que caracteriza a dicha novela como abandonada. Esto permite rescatar el significado léxico de base de dejar: 'soltar'. Por otro lado, en (18b), hay dos acciones independientes: la petición y el llanto de un caracol y el acto de Pablo de depositarlo en la arena. En esta estructura no hay interacción de los participantes. Con su acto, Pablo no provoca que llore el caracol y tampoco lo impide.

El esquema que se propone a continuación representa gráficamente la lectura no causal de las estructuras biclausales dejar + participio y dejar + gerundio:

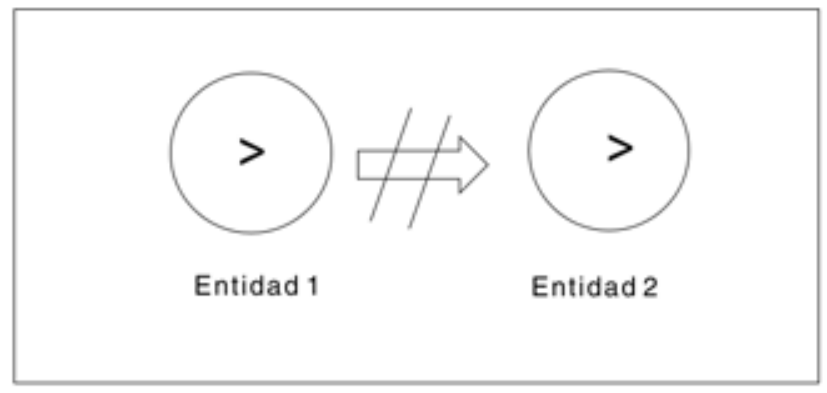

Esquema 4. Interacción nula entre participantes de eventos independientes

De acuerdo con el esquema 4, la entidad 1 con rasgos [+ humano] [+ activo] ejecuta una acción ( $>$ ) de manera independiente a la entidad 2 con rasgos [+ animado] [+ activo] que también es dinámico por su cuenta $(>)$. La flecha cancelada con líneas diagonales representa la ausencia de interacción entre ambos participantes. 


\subsection{Interpretación ambigua}

Por construcciones con ambigüedad semántica se han tomado aquellas estructuras que tienen una doble interpretación, es decir, una causativa positiva y otra independiente, como en (19):

Hizo un esfuerzo supremo y le levantó y le dejó desmayado sobre la cornisa

(CREA)

Esta construcción es ambigua puesto que le dejó desmayado sobre la cornisa puede interpretarse de dos maneras: una causativa positiva y otra, no causal, independiente. En la causativa se implica que el causante (él/ella) es quien provoca el desmayo del causado (él). Sin embargo, al reconocer que dejar no es un verbo léxico causativo prototípico, la primera interpretación que se infiere es la lectura no causal: el sujeto (él/ella) no provoca el desmayo del objeto directo (él), sólo lo levanta con esfuerzo y lo deposita, ya desmayado, en la cornisa. En esta lectura no hay causatividad y dejar mantiene su significado de base: 'soltar'.

La lectura con interpretación ambigua también está presente en el patrón sintáctico dejar + gerundio:

La primera interpretación de (20) es la no causativa. En ella prevalece el significado de una de las acepciones de dejar, esto es, 'alejarse', 'partir de un lugar', enriquecido con el carácter de continuidad de un evento que aporta el gerundio. Así, dejé hablando suma una serie de acciones separadas, sin que haya interacción entre sus participantes. Por un lado, se distingue una entidad 1 en primera persona de singular, codificada por las conjugaciones dejé y vine, correferida por el pronombre me, y una entidad 2, referente a una segunda/tercera persona de plural en masculino. En la lectura no causativa no hay interacción entre los participantes. El sujeto yo no provoca que ellos/ustedes hablen. Más bien debe inferirse que ya estaban hablando cuando la entidad 1 los deja, se va. Pero, puede interpretarse también 
que sea precisamente la entidad 1 la que provoque que ellos/ustedes hablen, propiciando la plática al reunirlos y una vez que la acción de hablar inicia, el sujeto se retira del lugar.

La diferencia principal entre las interpretaciones con significado claramente causativo y la lectura no causal radica, en primer lugar, en los rasgos de los participantes de la causación. En los ejemplos de (15) y (16), el significado causativo se debe a la imposición de la fuerza de un estímulo explícito - lexicalizado en sustantivos eventivos, así como de metonimias- con rasgos [- humano] sobre una entidad en reposo [- activo]. Incluso en los casos como (17), en que el causante es [+ humano] el contacto es indirecto, toda vez que lo que induce el cambio de estado es un estímulo que proviene de una acción previa no dirigida por el causante para generar dicho cambio de estado. Así que, en la medida en que en la entidad 1 ganan prominencia los rasgos [+ humano] [+ activo], la causatividad se pierde y hay una separación de eventos en que los participantes actúan de manera independiente.

Para la interpretación causativa positiva de dejar + participio/gerundio es necesario que el evento sea inducido por una fuerza o un impulso, pero no por un humano como causante directo del cambio de estado.

La diferencia puede apreciarse en los ejemplos (21a-d):

(21)a. El canto de Maricela dejó impactado al público

b. Maricela dejó impactado al público con su canto

c. La cantante dejó impactado al público

d. Maricela dejó impactado al público

En (21a), el sujeto causante (El canto de Maricela) es el estímulo explícito que favorece la lectura de la construcción como causativa positiva resultativa; de igual manera, en (21b), la interpretación de este tipo de causatividad es favorecida por la presencia del estímulo explícito a modo de oblicuo (con su canto), a pesar de que el sujeto causante (Maricela) cuenta con los rasgos [+ humano] [+ activo]. El caso de (21c) es distinto; los rasgos [+ humano] [+ activo] del sujeto causante (la cantante) podrían generar ambigüedad en la interpretación; no obstante, el sus- 
tantivo cantante sugiere principalmente que ha sido por su canto que los ha dejado impactados, ya que se perfila la zona activa (Langacker, 1991) de cantante que afecta de manera directa al causado. La zona activa es la parte directamente involucrada en una interacción que, a pesar de ser fundamental, nunca opera como figura primaria. En Juan escuchó el piano los oídos de Juan constituyen la zona activa, mientras que Juan es la figura primaria. En consecuencia, la zona activa puede quedar inferida o es codificada en frases oblicuas. En los ejemplos de (21b-c) la transmisión de energía para afectar al causado es su canto, ya sea como oblicuo (21b), ya como fuerza que se infiere de cantante (21c). En cambio, en (21d), los rasgos [+ humano] [+ activo] del causante (Maricela) son prominentes y ello hace que la interpretación causativa pierda claridad.

Lo anterior nos lleva a considerar que dejar es un verbo de causatividad positiva resultativa, siempre y cuando, en la construcción haya una causa explícita; de ahí la imperiosa necesidad de la presencia del estímulo como causante. Los casos en que hay un causante humano sólo forman construcciones causativas positivas cuando es la acción previa o una zona activa privilegiada la que induce de manera indirecta el cambio de estado. No es el agente sino su acción metonímica lo que puede operar como estímulo para provocar un cambio de estado, como en (16a-b y 21c) o para anular la claridad de la causatividad, como en (19-20).

\section{Conclusiones}

En dejar + participio y dejar + gerundio es imposible alcanzar los altos niveles de obligatoriedad de las estructuras factitivas, en las que el causante es agentivo y el causado tiene respuestas con distintos grados de actividad (incluida la resistencia). El punto causativo más alto de dejar + participio/gerundio se detiene en las reacciones, esto es, en respuestas provocadas por afectaciones mentales, emocionales, verbales, e incluso físicas. Por lo tanto, estas estructuras corresponden a una causatividad que hemos considerado 'baja'. Esta causatividad positiva baja de 
dejar + participio / dejar + gerundio abarca eventos con una imposición de fuerza que provoca cambios de estado, ya sea físicos, mentales o situacionales.

El significado esquemático causativo de dejar + participio/ gerundio corresponde a una causatividad positiva de índole resultativa, restringida por la manera en que se impone la fuerza, la naturaleza del verbo, los rasgos del causante como incitador del evento y las peculiaridades del causado para responder a la provocación a la que se le somete. Por un lado, la causatividad positiva resultativa se genera, siempre y cuando, en la cláusula exista un impulso, una causa explícita; de ahí la imperiosa necesidad de la presencia de un estímulo como causante [- humano] que impondrá su fuerza sobre una entidad en reposo [- dinámico] pero con propensión a sufrir cambios de estado.

La relación de causa y efecto es evidente en las estructuras analizadas sólo en el caso de que la imposición de fuerza pueda establecerse mediante el contacto directo entre causante y causado. Cuando no existe un contacto concreto entre los participantes, aparece un causante [+ humano] que se vale de una acción previa, convertida en estímulo para generar el cambio de estado en el causado. En la medida que en el causante aumentan los rasgos [+ humano] [+ dinámico] va generándose una separación de eventos, en la que se va diluyendo la lectura causativa y los participantes actúan de manera independiente.

Se puede concluir que dejar + participio y dejar + gerundio son patrones sintácticos con causatividad positiva resultativa, que requieren de causantes no humanos, justamente lo contrario de lo que se esperaría de las construcciones causativas prototípicas de nuestra lengua. Mientras las causativas fácticas toman agentes cuyos eventos causados se codifican con completivas con que + verbo en subjuntivo (hizo que saliera) o con verbos en infinitivo (lo hizo salir), la parte menos dinámica de la causatividad positiva ha quedado reservada para dejar + participios y gerundios cuyos causantes apenas alcanzan a tener la fuerza de un impulso. 


\section{Corpora}

Butragueño, M. y Lastra, Y. (2011). Corpus sociolingüístico de la ciudad de México. Materiales de PRESEEA-MÉXICO. México: El Colegio de México.

Davies, M. (2002). Corpus del Español: 100 million words, 1200s1900s. Recuperado de http://www.corpusdelespanol.org/ hist-gen/

Real Academia Española. Banco de datos (crea). Corpus de referencia del español actual. Recuperado de http://www. rae.es

\section{Referencias}

Comrie, B. (1976). The syntax of causatives constructions: cross language similarities and divergences. En M. Shibatani (ed.), The Grammar of Causative Constructions (pp. 259312). Nueva York: Academic Press.

Comrie, B. (1989). Causatives constructions. En B. Comrie, Language Universals and Linguistic Typology: Syntax and Morphology (2a ed.) (pp. 165-184). Chicago: The University Chicago Press.

Curnow, T. J. (1993). Semantics of Spanish causatives involving HACER. Australian Journal of Linguistics, 13(2), 165-184.

DAvies, M. (1995). The evolution of the Spanish causative constructions. Hispanic Review, 63, 57-77.

Dixon, R. \& Aikhenvald, A. (2000). A typology of causatives: form, syntax and meaning. En R. Dixon y A. Aikhenvald (eds.), Changing Valency: Case Studies in Transitivity (pp. 30-79). Cambridge: Cambridge University Press.

Enghels, R. (2012). Acusativo y dativo en la construcción factitiva: Hacia un replantamiento en términos multifactoriales. Revue Romane. Langue et Littérature. International Journal of Romance Languages and Literatures, 47(1), 1-24. Enghels, R. y Roegiest, E. (2012). Los verbos de causación negativa dejar y laisser: sintaxis y polisemia. En V. Bellosta von Colbe y M. García García (eds.), Aspectualidad, transi- 
tividad y referencialidad: Las lenguas románicas en contraste (pp. 87-119). Fráncfort del Meno: Peter Lang.

Enghels, R. (2013). Dejar: entre verbo causativo y verbo de control. Bulletin of Hispanics Studies, 90, 505-522.

GARcíA, A. (2013). Construing experience in Spanish: revisiting a systemic functional description of Spanish nuclear transitivity. Revista Signos. Estudios de Lingüística, 26(81), 29-55.

Gibson, J. y Raposo, E. (1986). Clause union, the stratal uniqueness law and the chômeur relation. Natural Languaje \& Linguistic Theory, 4(3), 295-331.

Givon, T. (2001). Syntax v. II. Ámsterdam: John Benjamins. LANGACKer, R.W. (1991). Active zones. En R. W. Langacker, Concept, Image and Symbol. The Cognitive Basics of Grammar (pp. 189-201). Berlín: Mouton de Gruyter.

López G., F. (2017). La construcción hacer + infinitivo: unas notas sobre matar y hacer morir. Anuari de Filología. Estudis de Lingüística, 7, 1-27.

Maldonado, R. (2000). Causatividad e (in)dependencia en el español de México. Anuario de Letras, XXXVIII, 231-308.

Maldonado, R. y Nava, F. (2002). Tarsacan causatives and event complexity. En M. Shibatani, The Grammar of Causation and Interpersonal Manipulation, 48 (pp. 157-195). Filadelfia: John Benjamins.

PARIS, L. (1999). The Spanish causative construction 'hacer + infinitive'. A role and reference grammar description. Inédito. Búfalo.

RodrígueZ-EspiñeIRA, M. J. (1999). Problemas de interpretación sintáctica en cláusulas con 'dejar + infinitivo'. En X. L. Couceiro et al. (eds.), Homenaxe ó profesor Camilo Flores (pp. 306-331). Santiago de Compostela: Universidad de Santiago.

Shibatani, M. (1976). The grammar of causatives constructions: A conceptus. En M. Shibatani (ed.), Syntax and Semantics. The Grammar of Causatives Constructions, 6 (pp. 1-40). Nueva York: Academic Press.

Shibatani, M. (2002). The Grammar of Causation and Interpersonal Manipulation. Filadelfia: John Benjamins. 
SoAres dA Silva, A. (2003). Image schemas and category coherence: The case of the Portuguese verb deixar. En H. Cuyckens, R. Dirven y J. R. Taylor (eds.), Cognitive Approaches to Lexical Semantics (pp. 281-298). Berlín/Nueva York: Mouton de Gruyter.

Soares da Silva, A. (2004a), 'Leave and keep thing as they are' from a force dynamic perspective. En P. Holz \& M. Plümacher Graumann (eds.), Towards a Dynamic Theory of Language (pp. 211-225). Bochum: Universitätsverlag Dr. N. Brockmeyer.

SoAres dA Silva, A. (2004b). Verbos y construcciones causativas analíticas en portugués y en español. En J. L. Cifuentes Honrubia y C. Marimón Llorca (eds.), Estudios de lingüística: El verbo (pp. 581-598). Alicante: Universidad de Alicante.

SoAres da Silva, A. (2007). Verbs of letting: some cogntive and historical aspects. En N. Delbecque y B. Cornillie (eds.) On Interpreting Construction Schemas: From Action and Motion to Transitivity and Causality (pp. 171-200). Berlín/ Nueva York: Mouton de Gruyter.

TAlmy, L. (1988). Force Dynamics in Language and Cognition. Cognitive Science, 12, 49-100.

Velázquez-Castillo, M. (2002). Guaraní causative constructions. En M. Shibatani, The Grammar of Causation and Interpersonal Manipulation, 48 (pp. 507-534). Filadelfia: John Benjamins.

Vera, L. A. (2018). Oraciones factitivas sintéticas y tipos de instrumentos en español. Verba, 45, 265-298.

Verhagen, A. y Kemmer, S. (1994). The grammar of causatives and the conceptual structure of events. Cognitive Linguistics, 5(2), 115-156.

Verhagen, A. y Kemmer, S. (1997). Interaction and causation: Causative constructions in modern. Journal of Pragmatics, 27, 61-82.

Vivanco G., J. M. (2016). Causatividad y cambio de estado en español. La alternancia causativo-inacusativa (tesis inédita de doctorado). Universidad Complutense de Madrid, Madrid, España. 